\title{
Peter Rose, How the Troubles Came to Northern Ireland, Londres: Macmillan, 2000
}

Paul Brennan

\section{OpenEdition}

1 Journals

Édition électronique

URL : http://journals.openedition.org/rfcb/708

DOI : $10.4000 /$ rfcb.708

ISSN : 2429-4373

Éditeur

CRECIB - Centre de recherche et d'études en civilisation britannique

Édition imprimée

Date de publication : 1 février 2002

Pagination : 100

ISBN : 2-911580-13-3

ISSN : 0248-9015

\section{Référence électronique}

Paul Brennan, «Peter Rose, How the Troubles Came to Northern Ireland, Londres: Macmillan, 2000 », Revue Française de Civilisation Britannique [En ligne], XI-3 | 2002, mis en ligne le 21 mars 2016, consulté le 25 septembre 2020. URL : http://journals.openedition.org/rfcb/708 ; DOI : https://doi.org/10.4000/ rfcb.708

Ce document a été généré automatiquement le 25 septembre 2020.

\section{(c) $(7)$}

Revue française de civilisation britannique est mis à disposition selon les termes de la licence Creative Commons Attribution - Pas d'Utilisation Commerciale - Pas de Modification 4.0 International. 


\title{
Peter Rose, How the Troubles Came to Northern Ireland, Londres: Macmillan, 2000
}

\author{
Paul Brennan
}

\section{RÉFÉRENCE}

Peter Rose, How the Troubles Came to Northern Ireland, Londres: Macmillan, 2000. £ 45.

ISBN 0-3337-5346-1.

1 Cet ouvrage, qui examine la politique des travaillistes envers l'Ulster entre 1964 et 1969, est largement inspiré par la thèse de l'auteur sur la politique nord-irlandaise de Harold Wilson. Il s'appuie sur des sources variées d'une grande solidité. Parmi celles-ci figurent, par exemple, des entretiens avec des ministres de l'époque, tels Roy Jenkins et James Callaghan, l'attaché de presse de Harold Wilson, Joe Haines, et des hauts fonctionnaires. Parmi les sources primaires officielles, Peter Rose s'appuie également sur les comptes rendus des réunions du cabinet publiés en 1997.

Dans l'introduction Peter Rose fait un bref historique de la politique irlandaise du parti travailliste entre 1921 et 1964 . Son approche chronologique s'allie à l'étude thématique. Celle-ci le conduit à insister sur la question de l'engagement électoral travailliste en 1964 d'opérer des réformes en Irlande du Nord; sur les renseignements reçus à Whitehall en 1965 quant à l'éventualité d'une explosion de violence; sur la réémergence du sectarisme et la mobilisation de la part des députés travaillistes à la Chambre en faveur de réformes en Ulster; sur la confiance faite par Wilson et son gouvernement à Terence O'Neill, premier ministre de l'Irlande du Nord, et, avant de conclure, sur la décision dramatique d'envoyer l'armée dans la province pour secourir les forces de l'ordre locales.

3 Il s'agit d'un livre important dans la mesure où il dresse une image de la façon dont le centre, Londres, gérait ses relations avec une partie de sa propre périphérie, Belfast, 
pendant un demi-siècle. Il y aura, sans doute, des leçons à en tirer par Londres quant à la nature des futurs rapports à entretenir avec Édimbourg, Cardiff et à nouveau Belfast. Bien que le thème traité ait déjà fait l'objet ici ou là d'une recherche soutenue, ce que Peter Rose semble ignorer, sa réponse à l'interrogation centrale sur les raisons qui ont empêché le gouvernement travailliste d'intervenir plus tôt en Irlande du Nord est complexe, nuancée et fondée sur une argumentation bâtie avec rigueur. Dans ses développements il apporte beaucoup d'éléments nouveaux. On apprend par exemple que le gouvernement refusa de laisser travailler le M15 en Irlande du Nord pour ne pas interférer dans le domaine de compétence de la RUC.

4 Sur le fond, l'auteur ne semble pas vouloir prendre parti en matière d'attribution de responsabilité. Ceci n'est pas sans poser problème puisque sa problématique centrale suggère qu'une intervention plus rapide eût évité la violence politique qui a déferlé sur la province par la suite. On a bien attribué des responsabilités au sujet de Munich en 1938, du Rwanda en 1994. Pourquoi ne pas en attribuer au sujet de l'Irlande du Nord dans les années 1960 ?

5 De plus, il ne se confronte pas à l'énormité de la volte-face opérée par le gouvernement en août 1969. L'écart entre ne rien faire et déployer l'armée dans les rues aurait mérité d'être saisi dans toutes ses implications. L'auteur avance un certain nombre de facteurs qui auraient empêché le premier ministre de se concentrer sur le problème nordirlandais : la confiance que Harold Wilson accordait à Terence $\mathrm{O}^{1} \mathrm{Neill}$, les conventions parlementaires à Westminster, le poids des circonstances, en Grande-Bretagne ou ailleurs. On aurait aimé une réflexion plus développée sur le thème des travaillistes et l'Union ainsi que sur les relations entre les gouvernements travaillistes de 1945-1951 et le Stormont. Une telle réflexion aurait permis à Peter Rose de donner une plus grande cohérence à la décision sciemment prise par Harold Wison de ne pas intervenir en Irlande du Nord. En dépit de ces critiques, ce livre constitue une contribution particulièrement importante à la compréhension de la politique britannique à l'égard de l'Irlande du Nord.

\section{AUTEURS}

\section{PAUL BRENNAN}

Université Paris III 